\title{
Comparative STUdy OF OPEN LOOP AND Closed loop Of Three Phase Active Power FACTOR CORRECTION BASED BUCK CONVERTER
}

\author{
Shobhit Jain ${ }^{1}$ \\ S.A.T.I.,Electrical Department, Vidisha, M.P , India
}

\begin{abstract}
-
Here with rapid growth in semi conducting devices the power loss is reduced and efficiency is increased.In this paper a open loop and closed loop of new three phase single switch active power factor correction $(A P F C)$ circuit based on quadratic (square)buck converter is proposed and analysed, through which we get extensive step down ratio and high power factor.The single-switch, quadratic step down dc-dc buck converter that can operate with input active power factor correction in both open loop and closed loop.Finally, this three-phase single switch quadratic buck APFC circuit was simulated using MATLAB/Simulink software. This result show that the power factor is high to 0.976 \& 0.999 in open loop and closed loop circuit and the total harmonic distortion (THD) is low to 3\% of the APFC converter. Comparative study of open loop and closed loop system of three phase single switch base on quadratic buck converter is showed \& Simulations and experimental results are given to verify the converter characteristics.
\end{abstract}

INDEX TERMS- open loop and closed loop,Power factor, quadratic buck converter, three-phase APFC circuit, total harmonics distortion (THD).

\section{INTRODUCTION}

With Rapid development In power Semiconductor devices, the usage of power electronic systems has expanded to new and wide application range that include residential, commercial, aerospace and traction system and SMPS. The current drawn by power semi converter devices from the lineis distorted resulting in a high Total Harmonic Distortion (THD) and low Power Factor(PF).Hence,there is a continuous need for power factor improvement and reduction of line current harmonics.[3]. During the last two decades, a great number of applications for the dc-to-dc converters have been reported. Many applications are found in computers, telecommunications, and aeronautic commercial and industrial applications. The basic topologies buck, boost, and buck-boost, are widely used in the dc-to-dc conversion. Converters, as well as other converters, provide low voltages and currents for loads at a constant switching frequency [7]. In recent years, there has been Need For wider conversion ratios with a corresponding reduction in size and weight. For example, advances in the field of semiconductors have motivated the development of new integrated circuits, which require 3.3 or $1.5 \mathrm{~V}$ power supplies. The conversion ratio of a quadratic buck converter equals square of the duty cycle, for example, for a 10:1 step down, a quadratic buck converter will operate with the duty cycle of 0.3. the traditional three-phase APFC circuit based on boost or buck converter, need to make the input filter capacitor work in discontinuous voltage mode (DCVM). In this way, APFC circuit with resistance load characteristics can achieve high power factor and low harmonic. 


\section{NEED For IMPROVEMENT OF POWER FACTOR}

Conventional AC rectification is thus a very in-efficient process,gives result in waveform distortion of the current drawn from the mains. That producing a large spectrum of harmonic signals that may interfere with other equipment. At higher power levels (200 to 500 watts and higher) severe interference with other electronic equipment may become apparent due to these harmonics sent into the power utility line. Thus, one Another problem is the power utility line cabling, \& the installation process and the distributing transformer, must be designed to withstand the peak current values results in higher electricity costs for any electricity utility company.

In Conventional AC rectification has the following main disadvantages:

- It creates harmonics and electromagnetic interference (EMI).

- It has poor power factor.

- It produces high losses.

- It requires extra dimensioning of parts.

- It reduces maximum power capability from the line.

\section{A. Active PFC Methods}

- An active approach is the most effective way to correct power factor of electronic supplies. Here, we place different Active PFC converters between the bridge rectifier and the load. The converter is trying to maintain a constant DC output bus voltage and draws a current that is in phase with and at the same frequency as the line voltage.

\section{ADVANTAGES:}

- Active wave shape of the input current.

- Filtration of the high frequency switching

- Feedback sensing of the source current for waveform controlling.

- Feedback controlling to regulate output voltage. 
i) Different load characteristics:

\section{Different Load Characteristic}

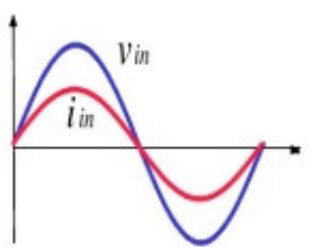

- Unity power factor

Resistance load

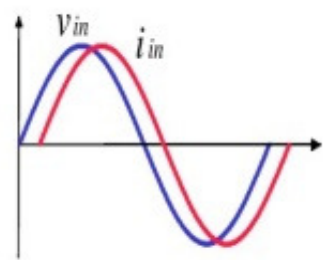

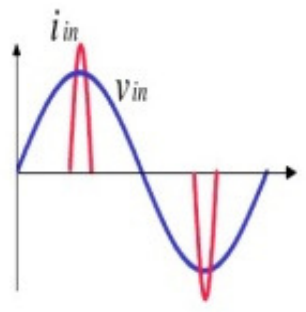

- Poor PF, THD $K_{\theta}=1$

Rectifier load with capacitor filter

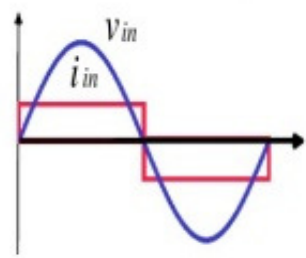

- Poor PF, good THD $K_{\theta}<1 \cdot$ Poor PF, THD $K_{\theta}=1$

Induction load

Rectifier load with inductor filter

Fig.1 different load charactersistics

ii) BLOCK DIAGRAM OF OPEN LOOP \& CLOSED LOOP THREE PHASE APFC BASED ON QUADRATIC BUCK CONVERTER:

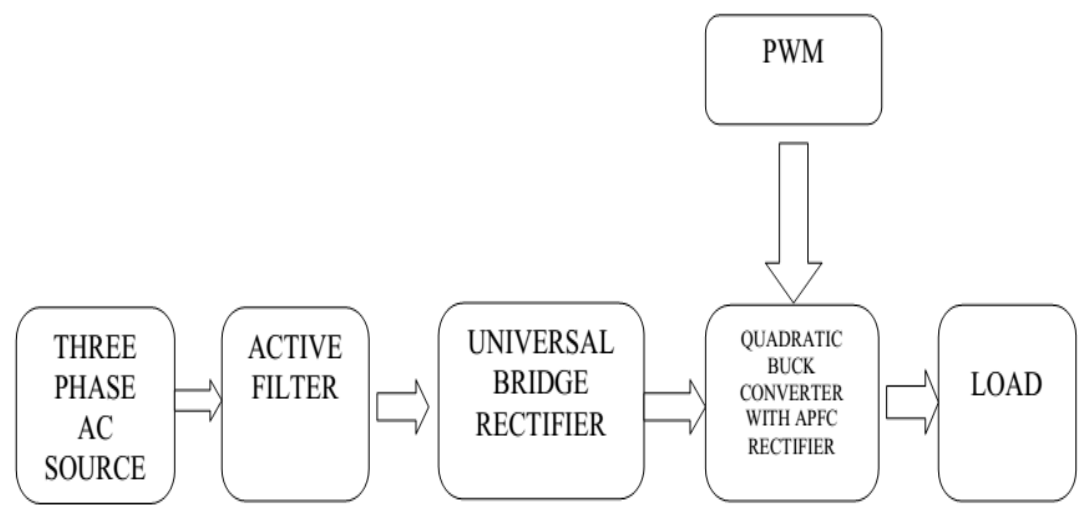

FIG.2 Block diagram of open loop circuit 


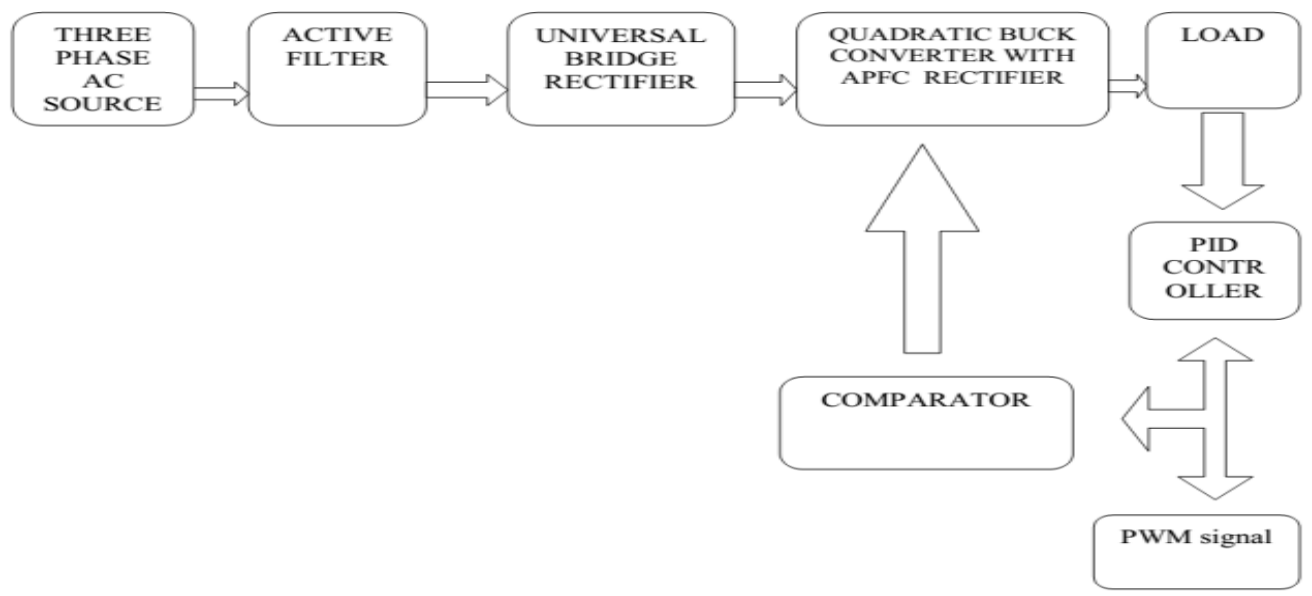

Fig3.Block diagram of closed loop circuit

\section{Working Principle Of Single Switch The Active Power FACTOR CirCuit BASED QuAdratic BuCK CONVERTER:}

The three phase APFC circuit based on quadratic buck converter has following three states:

(1). State $1\left(t_{0}<t \leq D_{1} T s\right)$

When switch $\mathrm{S}$ is 'on', D2 is the forward conduction, input capacitor is discharged, $\mathrm{C} 1$ is also in the discharge state. In this state, the voltage Vc across the capacitor is reduced to 0 .

(2). State 2:( $D_{1}$ Ts $<t \leq$ DTs $)$

When switch $S$ continues to maintain the 'on' state, the discharge process about the input capacitor is over, there is no current through the input capacitance, C1continues to discharge.

(3). State 3(DTs $<\mathrm{t} \leq \mathrm{Ts}$ )

When switch $\mathrm{S}$ is turned off, input capacitor begins to charge. At $\mathrm{t}=\mathrm{DTs}$, this process is over, and get into the next cycle.

Quadratic buck converter is a cascaded connection by two buck converter which contains two LC filter. In order to analysis and simplify modelling of quadratic buck converter can be referenced [1].

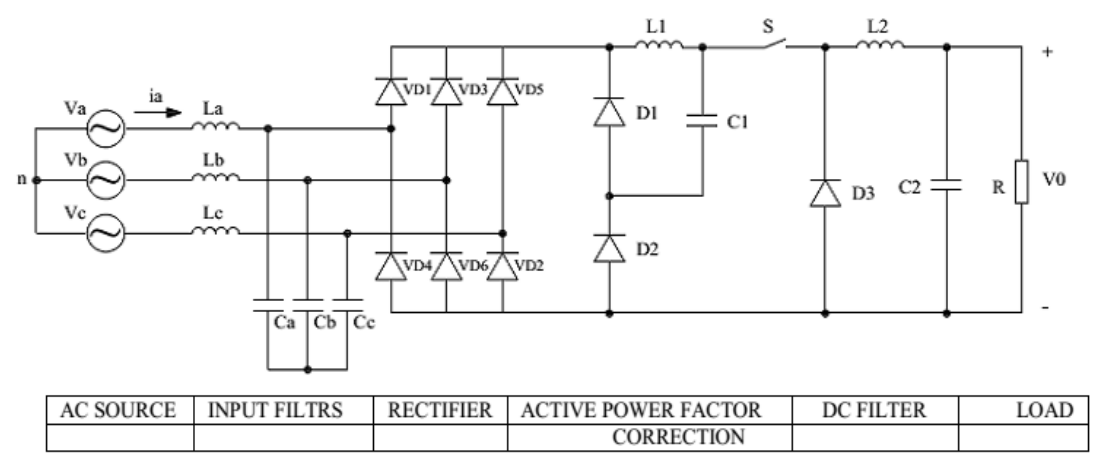

Fig.4 Three-phase single switch active power factor circuit (APFC) based on quadratic dc-dc step down Converter 
Electrical and Electronics Engineering: An International Journal (ELELIJ) Vol 4, No 1, February 2015

\section{Simulation And Analysis Of Three Phase Single Switch Active POWER FACTOR CORRECTION BASED QUADRATIC BuCK CONVERTER:}

The simulation of three phase model is constructed by MATLAB/simulink 2013a, The simulation model of 3-phase APFC circuit based on quadratic buck converter is constructed by MATLAB/ Simulink, the opened-loop and closed-loop simulation models are shown in fig.5 \& fig.6.here traditional pid controller is used in closed loop and switching frequency is 12 to $55 \mathrm{khz}$.

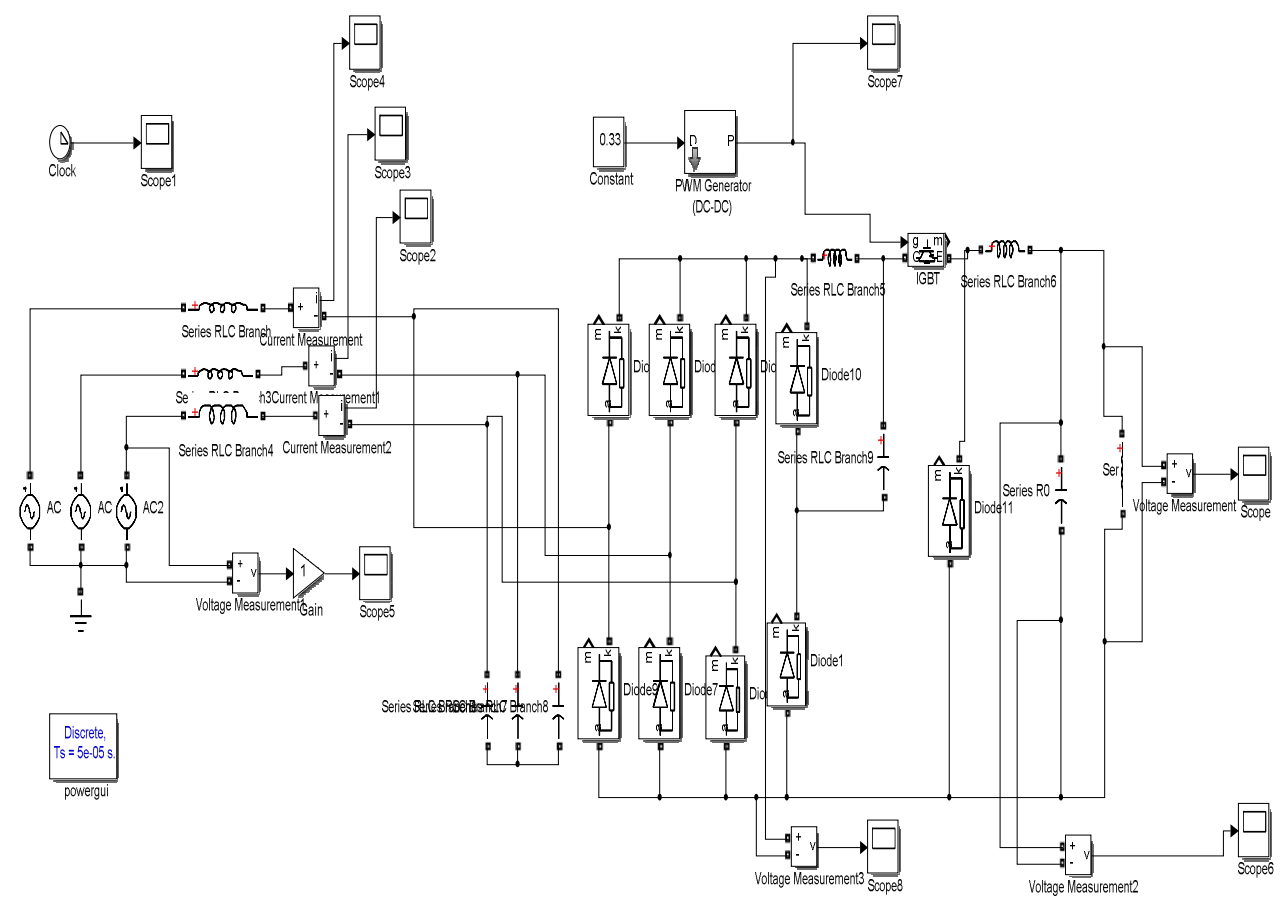

Fig.5 The opened-loop simulation model of 3-phases Quadratic Buck APFC Converter

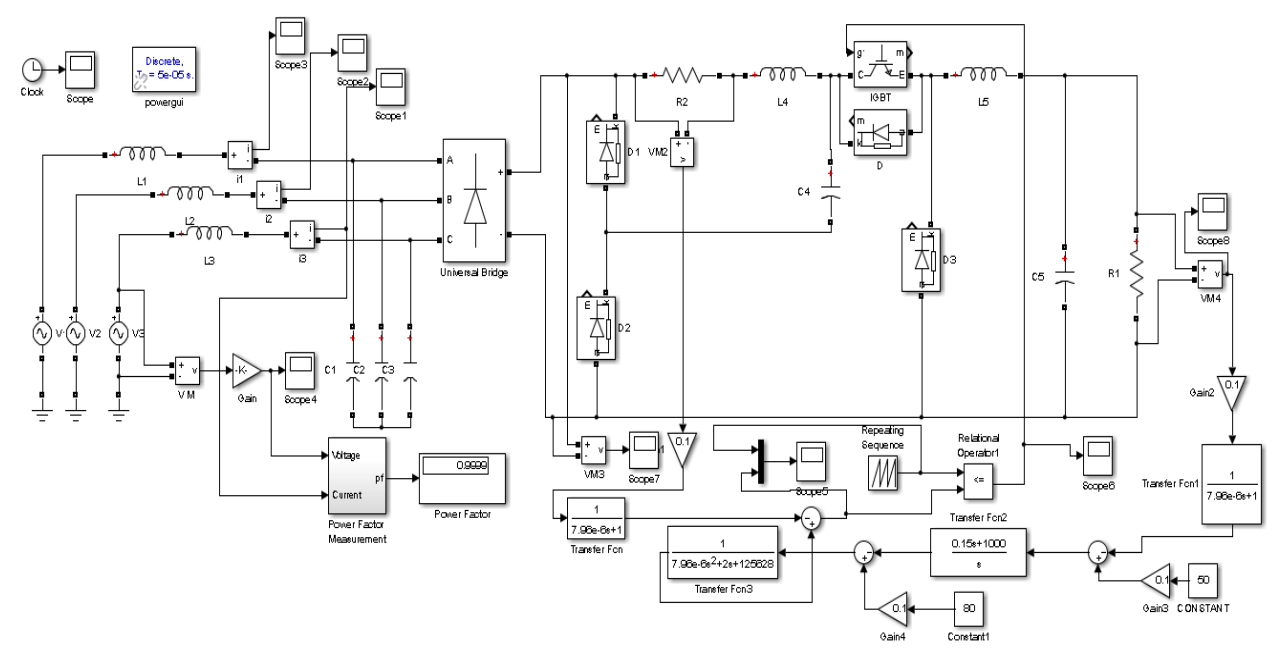

Fig.6 The Closed loop simulation model of three phase single switch Active power factor correction based on Quadratic buck converter 
In the simulation, the parameters of the quadratic Buck converter are selected as follows:

\begin{tabular}{|c|c|}
\hline L1,L2L3 & $5 \mathrm{mH}$ \\
\hline $\mathrm{C} 1, \mathrm{C} 2, \mathrm{C} 3$ & $0.2 \mu \mathrm{F}$ \\
\hline $\mathrm{L} 4$ & $0.22 \mathrm{mH}$ \\
\hline $\mathrm{L} 5$ & $20 \mu \mathrm{F}$ \\
\hline $\mathrm{C} 4$ & $19.3 \mu \mathrm{F}$ \\
\hline $\mathrm{C} 5$ & $13.4 \mu \mathrm{F}$ \\
\hline $\mathrm{R}$ & $1 \Omega$ \\
\hline
\end{tabular}

Table 1 parameters of circuit

From the simulation results Fig.6 with Fig.7, it showed that the input current waveform follows the input voltage waveform, the input current phase is coincident with the input voltage phase, and the input current waveform basically is a sine wave in closed-loop circuit, this simulation results verify that the above analysis is correct. In the case of opened-loop, as showed in Fig.5, the total harmonic distortion is $21.96 \%$, the power factor is about 0.976 . and in fig.6 case of closed-loop the total harmonic distortion is $3 \%$, and the power factor is about 0.999 . Therefore, the power factor of this three-phase APFC circuit based on quadratic buck converter is close to 1 or unity power factor.



Fig.7 Waveforms of opened-loop input voltage and current.

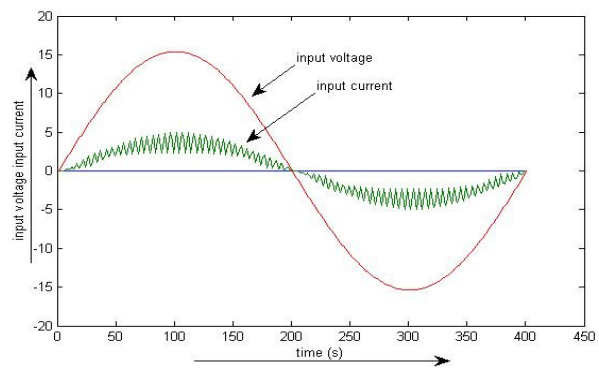

Fig.8 Waveforms of Closed-loop input voltage and current. 


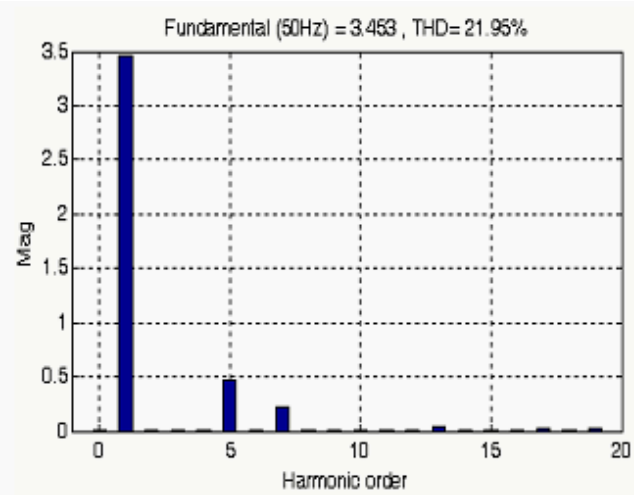

Fig.9 Input Current amplitude frequencies of opened-loop system.

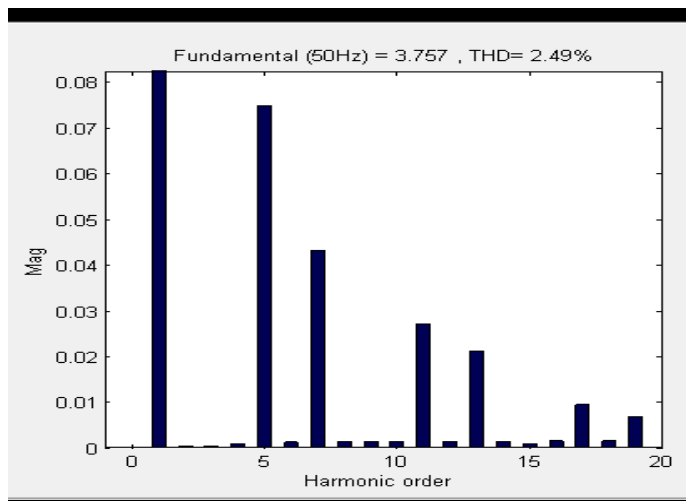

Fig.10 Input Current amplitude frequencies of Closed-loop system.

\section{CONCLUSION:}

This paper shows the comparative study of Open loop \& closed loop circuit theory of three phase single switch quadratic buck converter.here we get the highest power factor which is approximately unity. Finally, the input voltage and the input current waveforms are obtained by using the MATLAB/Simulink, and the input current harmonic orders are analyzed through the PowerGUI/FFT toolbox.finally the closed loop is better than the open loop where we get proper sinewave.

\section{REFERENCES:}

[1] K. Karaket, C. Bunlaksananusorn, "Modeling of a quadratic buck converter",2011 8th International Conference on ECTI-CON, pp. 764-767, 2011.

[2 ]"Robust Control Design and Implementation for a Quadratic Buck Converter" 978-1-4244-53931/10/\$26.00 @2010 IEEE

[3] “A Buck Quadratic PWM Soft-Switching Converter Using a Single Active Switch”Ieee Transactions On Power Electronics, Vol. 14, No. 3, May 1999

[4] Gao Xiaoqian," A study of Three-Phase APFC Based on Quadratic Buck Converter"Ieee Pes Isgt Asia 20121569576627

[5] "Analysis Of Different Topologiesfor Active Power Factor Orrection Using Dc Converters”Volume4, Issue1, Jan. 2014, ISSN No: 2250-3536, IJATER.

[6] "Comparative study of active power factor correction in ac-dc converters" international journal of electrical, electronics and datacommunication,ISSN:2320-2084,volume1,issue 1, march-2013

[7] Power electronics and applications by M.H Rashid "pearson publication 2010"

[8] Power electronics by P.S.bihmra 2010 
[9] Design And Simulation Of Three Phase Rectifier With Power Factor Correction" Electrical \& Electronic EngineeringTun Hussein Onn University of Malaysia ,july2012.

[10] Guo Qiong. "Using Power Graphical User Interface Capabilities of Matlab in Teaching of Power Engineering", Proceedings of Electric Power System and Automation, vol. 16 no. 02, pp. 80-84, Feb. 2004.

[11] Analysis of Quadratic Step-down DC-DC Converters Based on Noncascading Structures" 978-07695-4878-4/12 \$26.00 @ 2012 IEEE DOI 10.1109/CERMA.2012.80.

[12] "Modelling and Simulation of Three-Phase Single Switch Active Power Factor Correction Based Quadratic Buck Converter" International Journal of Engineering Research \& Technology (IJERT)Vol. 3 Issue 8, August - 2014 ISSN: 2278-0181.

[13] Power Electronics, Converters, Application and Design", Ned Mohan, Undeland, Robbins Wiley.

[14] A Comparative Study Of Three-Phase Single-Switch Buck Converters" Ccece/Ccgei May 5-7 2008 Niagara Falls. Canada978-1-4244-1643-1/08/\$25.00, Sondeep Bassan and Gerry Moschopoulos,2008 IEEE

[15] "A Three-Phase Single-Switch High Power Factor Buck-Type Converter Operating with SoftSwitching” 1-4244-0655-2/07/\$20.00@2007 IEEE, Sondeep Bassan and Gerry Moschopoulos.

[16] Modeling of a Single-Switch Quadratic Buck Converter” 0018-9251/05/\$17.00 c ²005 IEEE.

\section{Author Profile :}

Shobhit jain received the B.E in Electronics \& Communication from ACROPOLIS Institute bhopal and M.E. degree in POWER ELECTRONICS (Electrical Engineering) from Samrat Ashok Technological Institute vidisha (Since in 1960) in 2014, respectively.

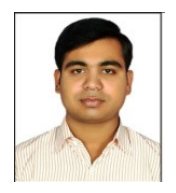

